\title{
Risk factors associated with bleeding after multi antithrombotic therapy during implantation of cardiac implantable electronic devices
}

\author{
Kohei Ishibashi $^{1,3} \cdot$ Koji Miyamoto $^{1}$ Tsukasa Kamakura $^{1} \cdot$ Mitsuru Wada $^{1}$ • \\ Ikutaro Nakajima ${ }^{1} \cdot$ Yuko Inoue $^{1} \cdot$ Hideo Okamura $^{1} \cdot$ Takashi Noda $^{1} \cdot$ Takeshi Aiba $^{1}$ \\ Shiro Kamakura ${ }^{1}$ - Wataru Shimizu ${ }^{1,2}$ - Satoshi Yasuda ${ }^{1}$ - Takashi Akasaka ${ }^{3}$. \\ Kengo Kusano ${ }^{1}$
}

Received: 19 January 2016 / Accepted: 22 July 2016 / Published online: 28 July 2016

(C) The Author(s) 2016. This article is published with open access at Springerlink.com

were associated with clinically significant $\mathrm{PH}(p=0.014$ and $p=0.015$, respectively). Continuous multi AT may be tolerated, but patients with high HAS-BLED score or VHD would require a careful attention during CIED implantations.

Keywords Cardiac surgery - Electrophysiology · Implanted cardiac defibrillators · Pacemakers

$\begin{array}{ll}\text { Abbreviations } \\ \text { ACE } & \text { Angiotensin converting enzyme } \\ \text { ANOVA } & \text { Analysis of variance } \\ \text { ARB } & \text { Angiotensin receptor blocker } \\ \text { AT } & \text { Antithrombotic therapy } \\ \text { BMI } & \text { Body mass index } \\ \text { CHF } & \text { Congestive heart failure } \\ \text { CI } & \text { Confidence interval } \\ \text { CIED } & \text { Cardiac implantable electronic device } \\ \text { CRT } & \text { Cardiac resynchronization therapy } \\ \text { CRT-D } & \text { Cardiac resynchronization therapy-defibrillator } \\ \text { CRT-P } & \text { Cardiac resynchronization therapy-pacemaker } \\ \text { DAPT } & \text { Dual antiplatelet therapy } \\ \text { DM } & \text { Diabetes mellitus } \\ \text { HT } & \text { Hypertension } \\ \text { ICD } & \text { Implantable cardioverter defibrillator } \\ \text { OAT } & \text { Oral anticoagulant therapy } \\ \text { NOAC } & \text { Novel oral anticoagulant } \\ \text { PH } & \text { Pocket hematoma } \\ \text { PM } & \text { Pacemaker } \\ \text { PT-INR } & \text { Prothrombin time-international ratio } \\ \text { SAPT } & \text { Single antiplatelet therapy } \\ \text { SD } & \text { Standard deviation } \\ \text { TAT } & \text { Triple antithrombotic therapy } \\ \text { TIA } & \text { Transient ischemic attack } \\ \text { VHD } & \text { Valvular heart disease } \\ & \end{array}$




\section{Introduction}

Current guidelines recommend that patients without a high thromboembolic risk should stop antithrombotic therapy (AT) because the implantation of cardiac implantable electronic devices (CIED) with the concomitant use of AT poses an increased risk of perioperative bleeding complications [1], but the interruption of antiplatelet and anticoagulant drugs increases thromboembolic events [2-5]. On the other hand, previous studies showed that continuous anticoagulation during CIED implantations was safe, and a previous report revealed that antiplatelet therapy should not be stopped before low-invasive surgeries because local hematomas are easy to control their bleeding [6-9]. Thus, continuous AT during CIED implantations has been recommended recently. In previous reports, a considerable number of patients with multi (dual or triple) AT were included. However, the safety of continuous multi AT in patients undergoing CIED implantations has not been sufficiently evaluated [10-13]. In this study, we sought to evaluate the safety of continuous multi AT during CIED implantations.

\section{Materials and methods}

\section{Patient population}

This study was a retrospective observational study. The study population consisted of consecutive patients who underwent CIED [pacemaker (PM), implantable cardioverter defibrillator (ICD), cardiac resynchronization therapy (CRT)-pacemaker (CRT-P), or CRT-defibrillator (CRT-D)] implantations without heparin bridging therapy in 2012. All patients who underwent the device surgery continued AT through the procedure. All patients underwent procedures with the standard techniques for a pectoral subfascial pocket formation and transvenous lead placement by way of the subclavian vein using tined or screw-in leads. All right atrial and right ventricular leads were positioned in the right auricular appendage and right ventricular apex, respectively. The left ventricular leads were positioned in the lateral, posterolateral, or anterior cardiac vein. Written informed consent was obtained from each patient in this study to undergo a CIED implantation. The privacy of the patients was protected by the anonymization of all data.

\section{Study protocol}

Three hundred patients were enrolled in this study. Patients were divided into 6 groups as follows; No-AT group: patients without any AT, OAT group: patients with oral anticoagulant therapy (OAT), SAPT group: patients with single antiplatelet therapy (SAPT), OAT + SAPT group: patients with OAT and SAPT, DAPT group: patients with dual antiplatelet therapy (DAPT), and TAT group: patients with triple antithrombotic therapy (TAT). They were evaluated for any perioperative complications (bleeding or thromboembolic events) occurring within 30 days of the surgery. Bleeding events included pocket hematomas (PH), clinically significant $\mathrm{PH}$, cerebral bleeding, gastrointestinal bleeding, and cardiac tamponade. The definition of PH was bleeding not requiring additional intervention but requiring treatment with compress. Clinically significant $\mathrm{PH}$ were defined as bleeding requiring surgical intervention, prolongation of hospitalization, interruption of AT, and blood product transfusions. Thromboembolic events included strokes, transient ischemic attacks (TIAs), myocardial infarctions, pulmonary embolisms, and deep vein thrombosis. Furthermore, the predictors of clinically significant $\mathrm{PH}$ were evaluated.

\section{Patient data collection and perioperative risk evaluation}

The patient characteristics, including the co-morbidities and medication history, and procedural details were collected at the time of the CIED implantation. The HASBLED [hypertension, abnormal renal/liver function, stroke, bleeding history or predisposition, labile international normalized ratio, elderly ( $>65$ years), drugs/ alcohol] score was used to assess the bleeding risk, and scored hypertension (HT), abnormal renal/liver function (1 point each), strokes, bleeding history or a predisposition to it, labile international normalized ratio, being elderly ( $>65$ years), and drugs/alcohol use (1 point each) [14]. If the HAS-BLED score was $\geq 3$, a patient was considered to have a considerable risk of bleeding [15-17]. Every thromboembolic risk factor was evaluated and we assessed the thromboembolic risk using the CHADS2 and CHA2DS2-VASc scores [14, 17-19]. The CHADS2 score assigned 1 point each for congestive heart failure (CHF), HT, age $\geq 75$ years, and diabetes mellitus (DM), and 2 points for a history of a stroke or TIA [14]. The CHA2DS2-VASc score assigned 1 point each for CHF, HT, age 65-74 years, DM, vascular disease, a female sex; and 2 points for an age $\geq 75$ years, and a history of a stroke or TIA [18]. If the CHA2DS2-VASc score was $\geq 2$, a patient was considered to have a considerable risk of a thromboembolism [19].

\section{Statistical analysis}

The statistical analyses were performed using JMP version 9 software (SAS Institute Inc., Tokyo, Japan). The results 
Table 1 Comparison of the clinical characteristics among No-AT, OAT, SAPT, OAT + SAPT, DAPT, and TAT groups

\begin{tabular}{|c|c|c|c|c|c|c|c|c|}
\hline & $\begin{array}{l}\text { Total } \\
(n=300)\end{array}$ & $\begin{array}{l}\text { No-AT } \\
(n=129)\end{array}$ & $\begin{array}{l}\text { OAT } \\
(n=89)\end{array}$ & $\begin{array}{l}\text { SAPT } \\
(n=49)\end{array}$ & $\begin{array}{l}\mathrm{OAT}+\mathrm{SAPT} \\
(n=20)\end{array}$ & $\begin{array}{l}\text { DAPT } \\
(n=10)\end{array}$ & $\begin{array}{l}\text { TAT } \\
(n=3)\end{array}$ & $p$ value \\
\hline Age (years) & $69 \pm 16$ & $66 \pm 19$ & $69 \pm 14$ & $75 \pm 11$ & $72 \pm 10$ & $65 \pm 12$ & $64 \pm 21$ & 0.017 \\
\hline Male & $171(57)$ & $68(53)$ & $41(46)$ & $34(69)$ & $15(75)$ & $10(100)$ & $3(100)$ & $<0.001$ \\
\hline Body height $(\mathrm{cm})$ & $159 \pm 11$ & $159 \pm 11$ & $158 \pm 10$ & $159 \pm 8$ & $162 \pm 10$ & $167 \pm 10$ & $166 \pm 3$ & 0.155 \\
\hline Body weight (kg) & $55 \pm 11$ & $55 \pm 11$ & $53 \pm 12$ & $56 \pm 10$ & $56 \pm 11$ & $62 \pm 9$ & $62 \pm 6$ & 0.101 \\
\hline BMI & $22 \pm 3$ & $22 \pm 3$ & $21 \pm 4$ & $22 \pm 3$ & $21 \pm 4$ & $22 \pm 2$ & $23 \pm 3$ & 0.349 \\
\hline $\begin{array}{l}\text { Serum creatinine } \\
(\mathrm{mg} / \mathrm{dl})\end{array}$ & $1.1 \pm 0.7$ & $0.9 \pm 0.4$ & $1.2 \pm 0.8$ & $1.4 \pm 1.1$ & $1.3 \pm 0.6$ & $1.0 \pm 0.2$ & $1.1 \pm 0.3$ & $<0.001$ \\
\hline $\begin{array}{l}\text { Blood hemoglobin } \\
(\mathrm{g} / \mathrm{dl})\end{array}$ & $12.7 \pm 1.8$ & $13.0 \pm 1.6$ & $12.6 \pm 1.8$ & $12.6 \pm 1.8$ & $12.5 \pm 2.2$ & $12.2 \pm 2.4$ & $12.4 \pm 1.4$ & 0.439 \\
\hline Diabetes mellitus & $68(23)$ & $16(12)$ & $19(21)$ & $18(37)$ & $9(45)$ & $5(50)$ & $1(33)$ & $<0.001$ \\
\hline Hypertension & $147(49)$ & $61(47)$ & $32(36)$ & $35(71)$ & $11(55)$ & $6(60)$ & $2(67)$ & 0.004 \\
\hline $\begin{array}{l}\text { Ischemic heart } \\
\text { disease }\end{array}$ & $54(18)$ & $3(2)$ & $2(2)$ & $26(53)$ & $11(55)$ & $9(90)$ & $3(100)$ & $<0.001$ \\
\hline $\begin{array}{l}\text { Valvular heart } \\
\text { disease }\end{array}$ & $23(8)$ & $2(2)$ & $18(20)$ & $1(2)$ & $2(10)$ & $0(0)$ & $0(0)$ & $<0.001$ \\
\hline Atrial fibrillation & $82(27)$ & $11(9)$ & $52(58)$ & $2(4)$ & $15(75)$ & $0(0)$ & $2(67)$ & $<0.001$ \\
\hline \multicolumn{9}{|l|}{ Drug } \\
\hline \multicolumn{9}{|l|}{ Anticoagulant drug } \\
\hline Warfarin & $107(36)$ & - & $85(96)$ & - & $19(95)$ & - & $3(100)$ & - \\
\hline $\begin{array}{l}\text { Control of } \\
\text { PT-INR }\end{array}$ & $1.7 \pm 0.4$ & - & $1.7 \pm 0.4$ & - & $1.8 \pm 0.5$ & - & $1.4 \pm 0.3$ & - \\
\hline NOAC & $5(1)$ & - & $4(4)$ & - & $1(5)$ & - & $0(0)$ & - \\
\hline \multicolumn{9}{|l|}{ Antiplatelet drug } \\
\hline Aspirin & $74(25)$ & - & - & $41(84)$ & $20(100)$ & $10(100)$ & $3(100)$ & - \\
\hline Thienopyridine & $13(4)$ & - & - & $2(4)$ & $0(0)$ & $8(80)$ & $3(100)$ & - \\
\hline Cilostazol & $8(3)$ & - & - & $6(12)$ & $0(0)$ & $2(20)$ & $0(0)$ & - \\
\hline$\beta$-Blocker & $138(46)$ & $39(30)$ & $55(62)$ & $23(47)$ & $13(65)$ & $6(60)$ & $2(67)$ & $<0.001$ \\
\hline $\begin{array}{l}\text { ACE inhibitor/ } \\
\text { ARB }\end{array}$ & $143(48)$ & $45(35)$ & $52(58)$ & $27(55)$ & $9(45)$ & $7(70)$ & $3(100)$ & 0.002 \\
\hline Statin & $101(34)$ & $27(21)$ & $25(28)$ & $29(59)$ & $10(50)$ & $7(70)$ & $3(100)$ & $<0.001$ \\
\hline Diuretics & $141(47)$ & $32(25)$ & $65(73)$ & $24(49)$ & $11(55)$ & $6(60)$ & $3(100)$ & $<0.001$ \\
\hline Amiodarone & $51(17)$ & $10(8)$ & $22(25)$ & $10(20)$ & $4(20)$ & $3(30)$ & $2(67)$ & 0.002 \\
\hline
\end{tabular}

Values are given as the $n(\%)$ or mean \pm standard deviation

$A C E$ angiotensin converting enzyme, $A R B$ angiotensin receptor blocker, $A T$ antithrombotic therapy, $B M I$ body mass index, $D A P T$ dual antiplatelet therapy, NOAC novel oral anticoagulant, $O A T$ oral anticoagulant therapy, $P T$-INR prothrombin time-international ratio, SAPT single antiplatelet therapy, TAT triple antithrombotic therapy

are expressed as the mean $\pm \mathrm{SD}$ for continuous variables. Categorical data are presented as numbers (\%). Differences among groups were analyzed by using the $t$-test for unpaired data, Chi-square test, and Fisher exact test, as appropriate. Differences in continuous variables were assessed using a one-way analysis of variance (ANOVA). A $p$ value $<0.05$ was considered significant. Logistic regression analysis was used to estimate the magnitude of association [i.e., odds ratios (ORs)] between clinically significant $\mathrm{PH}$ and clinical characteristics.

\section{Results}

\section{Clinical characteristics of No-AT, OAT, SAPT, OAT + SAPT, DAPT and TAT groups}

The baseline characteristics are listed in Table 1. The number of patients in No-AT, OAT, SAPT, OAT + SAPT, DAPT, and TAT groups was 129, 89, 49, 20, 10 and 3, respectively. The mean patient age was 69 years; 171 $(57 \%)$ were male. The frequency of ischemic heart disease, 
Table 2 Comparison of the procedural data among No-AT, OAT, SAPT, OAT + SAPT, DAPT, and TAT groups

\begin{tabular}{|c|c|c|c|c|c|c|c|c|}
\hline & $\begin{array}{l}\text { Total } \\
(\mathrm{n}=300)\end{array}$ & $\begin{array}{l}\text { No-AT } \\
(n=129)\end{array}$ & $\begin{array}{l}\text { OAT } \\
(n=89)\end{array}$ & $\begin{array}{l}\text { SAPT } \\
(n=49)\end{array}$ & $\begin{array}{l}\text { OAT }+ \text { SAPT } \\
(n=20)\end{array}$ & $\begin{array}{l}\text { DAPT } \\
(n=10)\end{array}$ & $\begin{array}{l}\text { TAT } \\
(n=3)\end{array}$ & $p$ value \\
\hline Type of CIED & & & & & & & & 0.522 \\
\hline PM and CRT-P & $167(56)$ & $75(58)$ & $52(58)$ & $27(55)$ & $8(40)$ & $4(40)$ & $1(33)$ & \\
\hline ICD and CRT-D & $133(44)$ & $54(42)$ & $37(42)$ & $22(45)$ & $12(60)$ & $6(60)$ & $2(67)$ & \\
\hline $\begin{array}{l}\text { De novo implanta- } \\
\text { tion }\end{array}$ & $190(63)$ & $78(60)$ & $54(61)$ & $35(71)$ & $13(65)$ & $7(70)$ & $3(100)$ & 0.540 \\
\hline System upgrade & $10(3)$ & $4(3)$ & $3(3)$ & $3(6)$ & $0(0)$ & $0(0)$ & $0(0)$ & 0.800 \\
\hline Procedure time $(\mathrm{h})$ & $1.8 \pm 0.9$ & $1.8 \pm 0.7$ & $1.9 \pm 1.1$ & $2.1 \pm 1.2$ & $1.9 \pm 0.7$ & $1.7 \pm 0.7$ & $2.3 \pm 0.9$ & 0.482 \\
\hline
\end{tabular}

Values are given as the $n(\%)$ or mean \pm standard deviation

$A T$ antithrombotic therapy, CIED cardiac implantable electronic device, $C R T-D$ cardiac resynchronization therapy-defibrillator, $C R T-P$ cardiac resynchronization therapy-pacemaker, $D A P T$ dual antiplatelet therapy, ICD implantable cardioverter-defibrillator, $O A T$ oral anticoagulant therapy, $P M$ pacemaker, $S A P T$ single antiplatelet therapy, TAT triple antithrombotic therapy

valvular heart disease (VHD), and atrial fibrillation was 18, 8 and $27 \%$, respectively. The rate of anticoagulant drug use was $37 \%$, and a novel oral anticoagulant (NOAC) use was observed in only 5 patients in this study. The prothrombin time-international ratio (PT-INR) as a warfarin control parameter was 1.7 and there was no significant difference in the PT-INR among OAT, OAT + SAPT, and TAT groups. The rate of antiplatelet drug use was $32 \%$.

\section{Procedural data of No-AT, OAT, SAPT, OAT + SAPT, DAPT and TAT groups}

The frequency of a large device (ICD and CRT-D), de novo implantation, and system upgrade were 44, 63 and $3 \%$, respectively. The mean procedure time was $1.8 \mathrm{~h}$. There were no significant differences among the 6 groups regarding the CRD type, rate of de novo implantations, system upgrades, or procedure time (Table 2).

\section{Bleeding and thromboembolic risk data of No-AT, OAT, SAPT, OAT + SAPT, DAPT, and TAT groups}

The bleeding and thromboembolic risk data of the 6 groups is shown in Table 3. The mean HAS-BLED score, $\mathrm{CHADS}_{2}$ score, and $\mathrm{CHA}_{2} \mathrm{DS}_{2}$-VASc score was $1.2,1.8$, and 3.2, respectively. HAS-BLED score $\geq 3$ as a high bleeding risk parameter was $21(7 \%)$ and significant difference among the 6 groups. CHA2DS2-VASc score $\geq 2$ as a considerable thromboembolic risk parameter was $247(82 \%)$ and significant difference among the 6 groups.

\section{Perioperative complication data of No-AT, OAT, SAPT, OAT + SAPT, DAPT, and TAT groups}

PH and clinically significant PH occurred $17(6 \%)$ and 9 (3\%) patients, respectively. The frequency of $\mathrm{PH}$ was significantly different, but the frequency of clinically significant
PH was not different among the 6 groups (Fig. 1). The gastrointestinal bleeding occurred $2(1 \%)$ and there was no significant difference among the 6 groups $(p=0.113)$. No subjects had any cardiac tamponade and cerebral bleeding.

Thromboembolic event occurred in only one patient and there was no significant difference in the frequency of that event among the 6 groups $(p=0.795)$.

\section{Predictors of clinically significant PH}

The frequency of VHD [OR 6.8; $95 \%$ confidence interval (CI) $1.4-27.8 ; p=0.010]$ or high HAS-BLED score (OR 2.2 ; $95 \%$ CI $1.1-4.3 ; p=0.021$ ) were major predictors of clinically significant $\mathrm{PH}$ by univariate analysis, as shown in Table 4 . In addition, low body mass index (OR 0.78; $95 \%$ CI $0.6-0.98 ; p=0.040$ ) was also a significant predictor of clinically significant $\mathrm{PH}$ by univariate analysis. The frequency of VHD (OR 7.2; $95 \%$ CI $1.3-35.0 ; p=0.015$ ) or high HASBLED score (OR 2.5; $95 \%$ CI 1.2-5.3; $p=0.014$ ) remained significant independent predictors of clinically significant $\mathrm{PH}$ developing by multivariate analysis.

\section{Discussion}

To the best of our knowledge, this is the first report on the comprehensive data concerning the safety of continuous multi AT during CIED implantations. The results of this study revealed that continuous multi AT was acceptable but high HAS-BLED and VHD were independent predictors of clinically significant PH during CIED implantations. These findings suggested that continuous multi AT may be tolerated, but patients with high HAS-BLED score or VHD would require a careful attention during CIED implantations.

Although the rate of clinically significant PH did not differ significantly among the 6 groups in our study, $5 \%$ of that complication rate in AT was relatively high. Previous 
Table 3 Comparison of the bleeding and thromboembolic risk data among No-AT, OAT, SAPT, OAT + SAPT, DAPT, and TAT groups

\begin{tabular}{|c|c|c|c|c|c|c|c|c|}
\hline & $\begin{array}{l}\text { Total } \\
(n=300)\end{array}$ & $\begin{array}{l}\text { No-AT } \\
(n=129)\end{array}$ & $\begin{array}{l}\text { OAT } \\
(n=89)\end{array}$ & $\begin{array}{l}\text { SAPT } \\
(n=49)\end{array}$ & $\begin{array}{l}\mathrm{OAT}+\mathrm{SAPT} \\
(n=20)\end{array}$ & $\begin{array}{l}\text { DAPT } \\
(n=10)\end{array}$ & $\begin{array}{l}\text { TAT } \\
(n=3)\end{array}$ & $p$ value \\
\hline \multicolumn{9}{|l|}{ Bleeding risk data } \\
\hline HAS-BLED score & $1.2 \pm 0.9$ & $0.8 \pm 0.7$ & $1.0 \pm 0.7$ & $2.0 \pm 0.8$ & $2.1 \pm 0.6$ & $2.0 \pm 1.0$ & $1.7 \pm 0.6$ & $<0.001$ \\
\hline HAS-BLED score $\geq 3$ & $21(7)$ & $2(2)$ & $3(3)$ & $10(20)$ & $2(10)$ & $4(40)$ & $0(0)$ & 0.001 \\
\hline \multicolumn{9}{|l|}{ Thromboembolic risk data } \\
\hline $\begin{array}{l}\text { Prior stroke/recurrent } \\
\text { venous thromboembolism }\end{array}$ & $34(11)$ & $4(3)$ & $14(16)$ & $8(16)$ & $7(35)$ & $0(0)$ & $1(33)$ & $<0.001$ \\
\hline Active cancer & $0(0)$ & $0(0)$ & $0(0)$ & $0(0)$ & $0(0)$ & $0(0)$ & $0(0)$ & - \\
\hline Thrombophilia & $0(0)$ & $0(0)$ & $0(0)$ & $0(0)$ & $0(0)$ & $0(0)$ & $0(0)$ & - \\
\hline $\mathrm{CHADS}_{2}$ score & $1.8 \pm 1.3$ & $1.2 \pm 1.2$ & $1.9 \pm 1.1$ & $2.5 \pm 1.3$ & $2.8 \pm 1.3$ & $1.8 \pm 0.8$ & $2.7 \pm 2.1$ & $<0.001$ \\
\hline $\mathrm{CHA}_{2} \mathrm{DS}_{2}$-VASc score & $3.2 \pm 1.8$ & $2.5 \pm 1.6$ & $3.3 \pm 1.5$ & $4.3 \pm 1.7$ & $4.7 \pm 1.6$ & $3.4 \pm 1.0$ & $4.3 \pm 2.5$ & $<0.001$ \\
\hline $\mathrm{CHA}_{2} \mathrm{DS}_{2}-$ VASc score $\geq 2$ & $247(82)$ & $88(68)$ & $80(90)$ & $47(96)$ & $19(95)$ & $10(100)$ & $3(100)$ & $<0.001$ \\
\hline
\end{tabular}

Values are given as the $n(\%)$ or mean \pm standard deviation

$A T$ antithrombotic therapy, DAPT dual antiplatelet therapy, OAT oral anticoagulant therapy, SAPT single antiplatelet therapy, TAT triple antithrombotic therapy

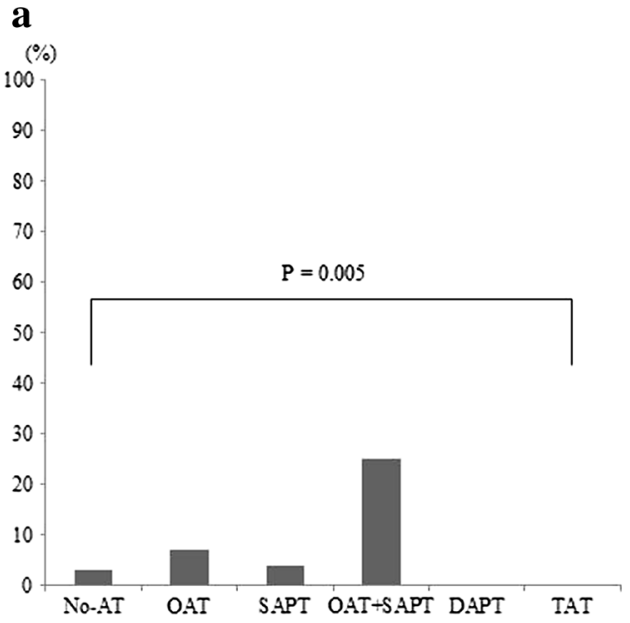

Fig. 1 a Pocket hematoma and clinically significant pocket hematoma among No-AT, OAT, SAPT, OAT + SAPT, DAPT, and TAT groups. The frequency of PH was 3, 7, 4, 25, 0 and $0 \%$ in No-AT, OAT, SAPT, OAT + SAPT, DAPT and TAT groups, respectively, and was significantly different among the 6 groups. b The frequency of clinically significant PH was 1, 6, 2, 10, 0 and $0 \%$ in No-AT, OAT,

studies revealed that a perioperative continuous single AT was associated with an incidence of PH of 1.9-6.6 \% [2027]. Thus, the clinically significant $\mathrm{PH}$ rate of the multi AT in our study may be acceptable.

The incidence of thromboembolic events was rare and did not differ significantly among the 6 groups in this study. The thromboembolic event rate of the single AT was $0-1 \%$ in previous studies [20-23]. Continuous multi AT may be effective in suppressing thromboembolic events within the perioperative period.

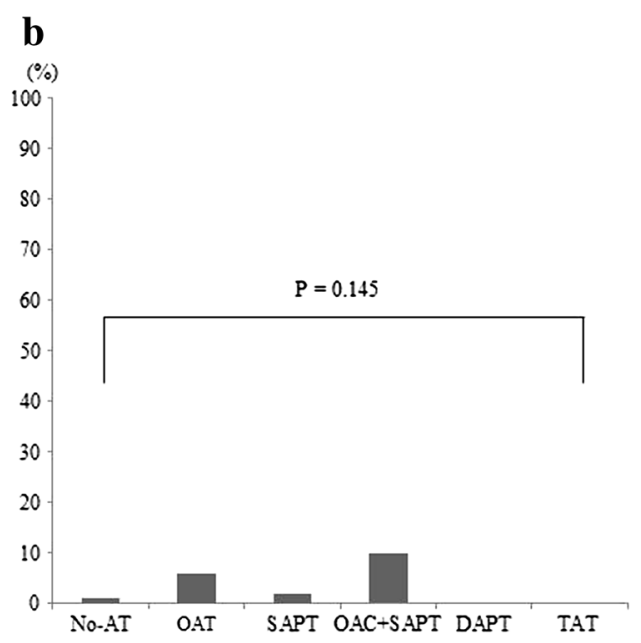

SAPT, OAT + SAPT, DAPT and TAT groups, respectively, and was not different among the 6 groups. AT antithrombotic therapy, DAPT dual antiplatelet therapy, $O A T$ oral anticoagulant therapy, $P H$ pocket hematoma, SAPT single antiplatelet therapy, TAT triple antithrombotic therapy

High HAS-BLED score and VHD were independent predictors of clinically significant PH during CIED implantations in this study. There is no report revealing that VHD is associated with bleeding complication during CIED implantations; however, one previous study said that the observed risk of bleeding was higher with AT in patients with VHD compared with patients without VHD [28]. Since VHD is a considerable disease, specific attention is needed in this population during CIED implantations. 
Table 4 Univariate and multivariate analyses of predictors of clinically significant $\mathrm{PH}$

\begin{tabular}{|c|c|c|c|c|c|c|}
\hline & \multicolumn{3}{|c|}{ Univariate analysis } & \multicolumn{3}{|c|}{ Multivariate analysis } \\
\hline & Odds ratio & $p$ value & $95 \% \mathrm{CI}$ & Odds ratio & $p$ value & $95 \% \mathrm{CI}$ \\
\hline Male gender & 2.71 & 0.219 & $0.64-18.40$ & & & \\
\hline Age (years) & 1.05 & 0.126 & $0.99-1.12$ & & & \\
\hline BMI & 0.78 & 0.040 & $0.61-0.98$ & 0.79 & 0.076 & $0.61-1.01$ \\
\hline Valvular heart disease & 6.77 & 0.010 & $1.35-27.79$ & 7.18 & 0.015 & $1.31-34.98$ \\
\hline Ischemic heart disease & 1.31 & 0.739 & $0.19-5.62$ & & & \\
\hline CHADS2 score & 1.28 & 0.317 & $0.77-2.04$ & & & \\
\hline HAS-BLED score & 2.20 & 0.021 & $1.11-4.33$ & 2.50 & 0.014 & $1.20-5.34$ \\
\hline High joule device & 1.59 & 0.495 & $0.41-6.54$ & & & \\
\hline Generator exchange & 2.21 & 0.244 & $0.57-9.11$ & & & \\
\hline Operation time (h) & 1.50 & 0.140 & $0.81-2.47$ & & & \\
\hline Blood hemoglobin (g/dl) & 0.85 & 0.387 & $0.57-1.23$ & & & \\
\hline Serum creatinine $(\mathrm{mg} / \mathrm{dl})$ & 1.19 & 0.624 & $0.42-2.03$ & & & \\
\hline
\end{tabular}

$B M I$ body mass index, $C I$ confidence interval
There were many warfarin users in our study, so our results are acceptable for patients with warfarin. The mean PT-INR of the warfarin users in this study was 1.7 and it was a low control level considering the previous data $[29,30]$. The bleeding risk in Asians is greater than that of the people in the other countries [31]. Previous Japanese registries revealed that a PT-INR of 1.6-2.6 was safe and effective in preventing thromboembolic events, particularly in patients aged $\geq 70$ years old [32-34]. The recommended PT-INR in the Japanese guidelines is 2.0-3.0 and 1.6-2.6 for patients aged $<70$ years and $\geq 70$ years, respectively [33]. Thus, our control level of the PT-INR was acceptable. In contrast, only $1 \%$ of the patients used NOACs, so we could not sufficiently evaluate the safety and efficacy of NOACs. Previous studies revealed that continuous NOAC use was safe during CIED implantations $[10,11]$. Thus, multi AT including NOACs may be safe and effective.

\section{Limitations}

There are several limitations to our study. The patient number in this study, especially for NOAC users, was very small. The evaluation of large number in this topic is needed by a future study. Furthermore, procedures performed by experienced operators carry a lower risk of clinically significant $\mathrm{PH}$ compared with trainees and less experienced operators [25, 26, 35]. Our hospital is a high-volume center (mean operation procedures, 500 per year) for CIED implantations, and experienced operators performed all surgeries in our study. A future multi-center study is needed to resolve this problem.

\section{Conclusions}

Continuous multi AT may be tolerated, but patients with high HAS-BLED score or VHD would require a careful attention during CIED implantations.

\section{Compliance with ethical standards}

\section{Sources of funding None.}

Conflict of interest All authors, do not have a financial interest/ arrangement or affiliation with one or more organizations that could be perceived as a real or apparent conflict of interest in the context of the subject of this article.

Open Access This article is distributed under the terms of the Creative Commons Attribution 4.0 International License (http://creativecommons.org/licenses/by/4.0/), which permits unrestricted use, distribution, and reproduction in any medium, provided you give appropriate credit to the original author(s) and the source, provide a link to the Creative Commons license, and indicate if changes were made.

\section{References}

1. Daubert JC, Saxon L, Adamson PB, Auricchio A, Berger RD, Beshai JF, Breithard O, Brignole M, Cleland J, Delurgio DB, Dickstein K, Exner DV, Gold M, Grimm RA, Hayes DL, Israel C, Leclercq C, Linde C, Lindenfeld J, Merkely B, Mont L, Murgatroyd F, Prinzen F, Saba SF, Shinbane JS, Singh J, Tang AS, Vardas PE, Wilkoff BL, Zamorano JL (2012) 2012 EHRA/HRS expert consensus statement on cardiac resynchronization therapy in heart failure: implant and follow-up recommendations and management. Heart Rhythm 9:1524-1576

2. Stone GW, Aronow HD (2006) Long-term care after percutaneous coronary intervention: focus on the role of antiplatelet therapy. Mayo Clin Proc 81:641-652 
3. Popma JJ, Berger P, Ohman EM, Harrington RA, Grines C, Weitz JI (2004) Antithrombotic therapy during percutaneous coronary intervention: the seventh ACCP conference on antithrombotic and thrombolytic therapy. Chest 126:576s-599s

4. Suh SY, Kang WC, Oh PC, Choi H, Moon CI, Lee K, Han SH, Ahn T, Choi IS, Shin EK (2014) Efficacy and safety of aspirin, clopidogrel, and warfarin after coronary artery stenting in Korean patients with atrial fibrillation. Heart Vessels 29:578-583

5. Hamatani Y, Iguchi M, Nakamura M, Ohtani R, Yamashita Y, Takagi D, Unoki T, Ishii M, Masunaga N, Ogawa H, Hamatani M, Abe M, Akao M (2015) Incidence and predictors of ischemic stroke during hospitalization for congestive heart failure. Heart Vessels. doi:10.1007/s00380-015-0719-4

6. Birnie DH, Healey JS, Wells GA, Verma A, Tang AS, Krahn AD, Simpson CS, Ayala-Paredes F, Coutu B, Leiria TL, Essebag V (2013) Pacemaker or defibrillator surgery without interruption of anticoagulation. N Engl J Med 368:2084-2093

7. Rowley CP, Bernard ML, Brabham WW, Netzler PC, Sidney DS, Cuoco F, Sturdivant JL, Leman RB, Wharton JM, Gold MR (2013) Safety of continuous anticoagulation with dabigatran during implantation of cardiac rhythm devices. Am J Cardiol 111:1165-1168

8. Kosiuk J, Koutalas E, Doering M, Sommer P, Rolf S, Breithardt OA, Nedios S, Dinov B, Hindricks G, Richter S, Bollmann A (2014) Treatment with novel oral anticoagulants in a real-world cohort of patients undergoing cardiac rhythm device implantations. Europace 16:1028-1032

9. Kosiuk J, Koutalas E, Doering M, Nedios S, Sommer P, Rolf S, Darma A, Breithardt OA, Dinov B, Hindricks G, Richter S, Bollmann A (2014) Comparison of dabigatran and uninterrupted warfarin in patients with atrial fibrillation undergoing cardiac rhythm device implantations. Case-control study. Circ J 78:2402-2407

10. Zacà V, Marcucci R, Parodi G, Limbruno U, Notarstefano P, Pieragnoli P, Di Cori A, Bongiorni MG, Casolo G (2015) Management of antithrombotic therapy in patients undergoing electrophysiological device surgery. Europace 17:840-854

11. Sticherling C, Marin F, Birnie D, Boriani G, Calkins H, Dan GA, Gulizia M, Halvorsen S, Hindricks G, Kuck KH, Moya A, Potpara T, Roldan V, Tilz R, Lip GYH (2015) Antithrombotic management in patients undergoing electrophysiological procedures: a European Heart Rhythm Association (EHRA) position document endorsed by the ESC Working Group Thrombosis, Heart Rhythm Society (HRS), and Asia Pacific Heart Rhythm Society (APHRS). Europace 17:1197-1214

12. Lip GYH, Windecker S, Huber K, Kirchhof P, Marin F, TenBerg JM, Haeusler KG, Boriani G, Capodanno D, Gilard M, Zeymer U, Lane D (2014) Management of antithrombotic therapy in atrial fibrillation patients presenting with acute coronary syndrome and/or undergoing percutaneous coronary or valve interventions: a joint consensus document of the European Society of Cardiology Working Group on Thrombosis, European Heart Rhythm Association (EHRA), European Association of Percutaneous Cardiovascular Interventions (EAPCI) and European Association of Acute Cardiac Care (ACCA) endorsed by the Heart Rhythm Society (HRS) and Asia-Pacific Heart Rhythm Society (APHRS). Eur Heart J 35:3155-3179

13. Yang X, Wang Z, Zhang Y, Yin X, Hou Y (2015) The safety and efficacy of antithrombotic therapy in patients undergoing cardiac rhythm device implantation: a meta-analysis. Europace 17:1076-1084

14. Gage BF, Waterman AD, Shannon W, Boechler M, Rich MW, Radford MJ (2001) Validation of clinical classification schemes for predicting stroke: results from the National Registry of Atrial Fibrillation. JAMA 285:2864-2870

15. Camm AJ, Lip GY, De Caterina R, Savelieva I, Atar D, Hohnloser SH, Hindricks G, Kirchhof P (2012) 2012 focused update of the ESC Guidelines for the management of atrial fibrillation: an update of the 2010 ESC Guidelines for the management of atrial fibrillation. Developed with the special contribution of the European Heart Rhythm Association. Eur Heart J 33:2719-2747

16. Lip GY, Frison L, Halperin JL, Lane DA (2011) Comparative validation of a novel risk score for predicting bleeding risk in anticoagulated patients with atrial fibrillation: the HAS-BLED (Hypertension, Abnormal Renal/Liver Function, Stroke, Bleeding History or Predisposition, Labile INR, Elderly, Drugs/Alcohol Concomitantly) score. J Am Coll Cardiol 57:173-180

17. Lane DA, Lip GY (2012) Use of the CHA(2)DS(2)-VASc and HAS-BLED scores to aid decision making for thromboprophylaxis in nonvalvular atrial fibrillation. Circulation 126:860-865

18. Lip GY, Nieuwlaat R, Pisters R, Lane DA, Crijns HJ (2010) Refining clinical risk stratification for predicting stroke and thromboembolism in atrial fibrillation using a novel risk factorbased approach: the euro heart survey on atrial fibrillation. Chest 137:263-272

19. Douketis JD, Spyropoulos AC, Spencer FA, Mayr M, Jaffer AK, Eckman MH, Dunn AS, Kunz R, American Collegeof Chest Physicians (2012) Perioperative management of antithrombotic therapy: Antithrombotic Therapy and Prevention of Thrombosis, 9th ed: American College of Chest Physicians Evidence-Based Clinical Practice Guidelines. Chest 141:e326S-e350S

20. Jamula E, Douketis JD, Schulman S (2008) Perioperative anticoagulation in patients having implantation of a cardiac pacemaker or defibrillator: a systematic review and practical management guide. J Thromb Haemost 6:1615-1621

21. Al-Khadra AS (2003) Implantation of pacemakers and implantable cardioverter defibrillators in orally anticoagulated patients. Pacing Clin Electrophysiol 26:511-514

22. Giudici MC, Paul DL, Bontu P, Barold SS (2004) Pacemaker and implantable cardioverter defibrillator implantation without reversal of warfarin therapy. Pacing Clin Electrophysiol 27:358-360

23. Goldstein DJ, Losquadro W, Spotnitz HM (1998) Outpatient pacemaker procedures in orally anticoagulated patients. Pacing Clin Electrophysiol 21:1730-1734

24. Tompkins C, Cheng A, Dalal D, Brinker JA, Leng CT, Marine JE, Nazarian S, Spragg DD, Sinha S, Halperin H, Tomaselli GF, Berger RD, Calkins H, Henrikson CA (2010) Dual antiplatelet therapy and heparin "bridging" significantly increase the risk of bleeding complications after pacemaker or implantable cardioverter-defibrillator device implantation. J Am Coll Cardiol 55:2376-2382

25. Korantzopoulos P, Letsas KP, Liu T, Fragakis N, Efremidis M, Goudevenos JA (2011) Anticoagulation and antiplatelet therapy in implantation of electrophysiological devices. Europace 13:1669-1680

26. Wiegand UK, LeJeune D, Boguschewski F, Bonnemeier H, Eberhardt F, Schunkert H, Bode F (2004) Pocket hematoma after pacemaker or implantable cardioverter defibrillator surgery: influence of patient morbidity, operation strategy, and perioperative antiplatelet/anticoagulation therapy. Chest 126:1177-1186

27. Klug D, Balde M, Pavin D, Hidden-Lucet F, Clementy J, Sadoul N, Rey JL, Lande G, Lazarus A, Victor J, Barnay C, Grandbastien B, Kacet S (2007) Risk factors related to infections of implanted pacemakers and cardioverter-defibrillators: results of a large prospective study. Circulation 116:1349-1355

28. Breithardt G, Baumgartner H, Berkowitz SD, Hellkamp AS, Piccini JP, Stevens SR, Lokhnygina Y, Patel MR, Halperin JL, Singer DE, Hankey GJ, Hacke W, Becker RC, Nessel CC, Mahaffey KW, Fox KA, Califf RM, ROCKETAF Steering Committee Investigators (2014) Clinical characteristics and outcome with rivaroxaban vs. warfarin in patients with non-valvular atrial fibrillation but underlying native mitral and aortic valve disease participating in the ROCKET AF trial. Eur Heart J 35:3377-3385 
29. Hart RG, Sherman DG, Easton JD, Cairns JA (1998) Prevention of stroke in patients with nonvalvular atrial fibrillation. Neurology 51:674-681

30. Hylek EM, Skates SJ, Sheehan MA, Singer DE (1996) An analysis of the lowest effective intensity of prophylactic anticoagulation for patients with nonrheumatic atrial fibrillation. $\mathrm{N}$ Engl $\mathrm{J}$ Med 335:540-546

31. Shen AY, Yao JF, Brar SS, Jorgensen MB, Chen W (2007) Racial/ ethnic differences in the risk of intracranial hemorrhage among patients with atrial fibrillation. J Am Coll Cardiol 50:309-315

32. Yasaka M, Minematsu K, Yamaguchi T (2001) Optimal intensity of international normalized ratio in warfarin therapy for secondary prevention of stroke in patients with non-valvular atrial fibrillation. Intern Med 40:1183-1188
33. Inoue $\mathrm{H}$, Atarashi $\mathrm{H}$, Kamakura S, Koretsune Y, Kumagai K, Mitamura H, Okumura K, Sugi K, Yamashita T, Yasaka M, Satomi K, Kodama I, Ogawa S, Ohe T, Tsutsui H (2014) Guidelines for pharmacotherapy of atrial fibrillation (JCS 2013). Circ J 78:1997-2021

34. JCS Joint Working Group (2013) Target international normalized ratio values for preventing thromboembolic and hemorrhagic events in Japanese patients with non-valvular atrial fibrillation: results of the J-RHYTHM Registry. Circ J 77:2264-2270

35. Tolosana JM, Berne P, Mont L, Heras M, Berruezo A, Monteagudo J, Tamborero D, Benito B, Brugada J (2009) Preparation for pacemaker or implantable cardiac defibrillator implants in patients with high risk of thrombo-embolic events: oral anticoagulation or bridging with intravenous heparin? A prospective randomized trial. Eur Heart J 30:1880-1884 